\title{
Low-Dose Aspirin and Small Bowel Enteropathy: Mountain or Molehill?
}

\author{
Robert Benamouzig \\ Service de Gastroentérologie, Hôpital Avicenne, Bobigny, France
}

Aspirin is one of the most widely used medications in the world, with an estimated 40,000 metric tons being consumed every year. In contrast to many other classes of drugs, aspirin is available both in prescription and over-the-counter formulations. Aspirin is one of the most frequently used drugs in the treatment of mild to moderate pain, including that of migraine and fever. At higher doses, aspirin is used in the treatment of inflammatory joint conditions. At lower doses, aspirin inhibits platelet aggregation and has been shown to reduce the incidence of transient ischemic attacks and coronary artery disease. Low doses of aspirin are recommended for the prevention of stroke and myocardial infarction in patients with diagnosed cardiovascular disease. The role of aspirin in reducing the incidence of various forms of cancer including colorectal cancer has also been widely studied. Aspirin including low-dose aspirin use has been shown to increase the risk of gastroduodenal ulcers and bleeding. Until recently, aspirin has been regarded, at least by some authors, as safe for small bowel beyond the duodenum [1]. The topical effect of aspirin was estimated to be mainly limited to the gastroduodenum due to the rapid absorption of aspirin in the stomach and duodenum, and the lack of an enterohepatic cycle. The effects of small bowel aspirin were previously evaluated in humans by measurement of intestinal permeability or surrogate markers of inflammation in stools. Studies looking at enteropathy were performed in a limited number of aspirin users and showed little evidence for increased intestinal permeability [2-5]. A dose effect could be expected since acetylsalicylic acid $3 \mathrm{~g}$ daily was associated with a lactulose/mannitol ratio $118 \%$ higher than after placebo [6]. Aspirin was reported to be associated with an increased risk of lower gastrointestinal bleeding in 7 out of 8 case-control studies [7], but a large-scale 48month trial failed to demonstrate such an effect [8]. Aspirin's small bowel effects were evaluated at enteroscopy, surgery or post-mortem, suggesting an increased risk for perforation and bleeding $[9,10]$. Diaphragm-like strictures in the small bowel were reported in long-term aspirin users [11]. The study of Endo et al. [12] in this issue of Digestion showed that low-dose aspirin is associated with mild mucosal damages exhibited by capsule endoscopy in $80 \%$ of 10 healthy volunteers after 2 weeks of treatment. These results are consistent with those reported by Watanabe et al. [13] in 11 patients with gastroduodenal ulcers who underwent capsule endoscopy and those reported by Matsumoto et al. [14] where doubleballoon enteroscopy was used. However, the clinical value of these preliminary findings remains questionable. In fact, most of the observed lesions healed spontaneously within the 4-week washout period of this crossover study. Whether these lesions are putative precursors of relevant small bowel damage remains an open issue. We are confident that further, larger studies allowing the wide use of capsule endoscopy combined with long-term follow-up will give an answer to this important question.

\section{KARGER}

Fax +41613061234 E-Mail karger@karger.ch www.karger.com
(C) 2009 S. Karger AG, Basel

0012-2823/09/0791-0040\$26.00/0

Accessible online at:

www.karger.com/dig
Robert Benamouzig

Service de Gastroentérologie, Hôpital Avicenne

125 , rue de Stalingrad, FR-93009 Bobigny Cedex (France)

E-Mail robert.benamouzig@avc.aphp.fr 


\section{References}

1 Thiefin G: Low-dose aspirin and small bowel enteropathy. Lancet 2007;369:1690-1691.

-2 Bjarnason I, Williams P, Smethurst P, Peters TJ, Levi AJ: Effect of non-steroidal anti-inflammatory drugs and prostaglandins on the permeability of the human small intestine. Gut 1986;27:1292-1297.

-3 Sigthorsson G, Tibble J, Hayllar J, Menzies I, Macpherson A, Moots R, Scott D, Gumpel MJ, Bjarnason I: Intestinal permeability and inflammation in patients on NSAIDs. Gut 1998;43:506-511.

4 Catanoso M, Lo Gullo R, Giofré MR, Pallio S, Tortora A, Lo Presti M, Frisina N, Bagnato $\mathrm{G}$, Fries W: Gastrointestinal permeability is increased in patients with limited systemic sclerosis. Scand J Rheumatol 2001;30:77-81.

5 Jenkins RT, Rooney PJ, Jones DB, Bienenstock J, Goodacre RL: Increased intestinal permeability in patients with rheumatoid arthritis: a side-effect of oral non-steroidal anti-inflammatory drug therapy? Br J Rheumatol 1987;26:103-107.

-6 Twiss IM, Burggraaf J, Schoemaker RC, van Elburg RM, den Hartigh J, Cohen AF, Vermeij P: The sugar absorption test in the evaluation of the gastrointestinal intolerance to bisphosphonates: studies with oral pamidronate. Clin Pharmacol Ther 2001;69:431437.
7 Laine L, Smith R, Min K, Chen C, Dubois RW: Systematic review: the lower gastrointestinal adverse effects of non-steroidal antiinflammatory drugs. Aliment Pharmacol Ther 2006;24:751-767.

8 Langman MJ, Morgan L, Worrall A: Use of anti-inflammatory drugs by patients admitted with small or large bowel perforations and haemorrhage. Br Med J 1985;290:347349.

$\checkmark 9$ Allison MC, Howatson AG, Torrance CJ, Lee FD, Russell RI: Gastrointestinal damage associated with the use of nonsteroidal antiinflammatory drugs. N Engl J Med 1992;327: 749-754.

10 Zalev AH, Gardiner GW, Warren RE: NSAID injury to the small intestine. Abdom Imaging 1998;23:40-44.
$>11$ Slattery J, Warlow CP, Shorrock CJ, Langman MJ: Risks of gastrointestinal bleeding during secondary prevention of vascular events with aspirin - analysis of gastrointestinal bleeding during the UK-TIA trial. Gut 1995;37:509-511.

12 Endo $\mathrm{H}$, Hosono K, Inamori M, Kato S, Nozaki Y, Yoneda K, Akiyama T, Fujita K, Takahashi H, Yoneda M, Abe Y, Kirikoshi H, Kobayashi N, Kubota K, Saito S, Matsuhashi N, Nakajima A: Incidence of small bowel injury induced by low-dose aspirin: a crossover study using capsule endoscopy in healthy volunteers. Digestion 2009;79:44-51.

$\checkmark 13$ Watanabe T, Sugimori S, Kameda N, Machida H, Okazaki H, Tanigawa T, Watanabe K, Tominaga K, Fujiwara Y, Oshitani N, Higuchi K, Arakawa T: Small bowel injury by lowdose enteric-coated aspirin and treatment with misoprostol: a pilot study. Clin Gastroenterol Hepatol 2008;6:1279-1282.

-14 Matsumoto T, Kudo T, Esaki M, Yano T, Yamamoto H, Sakamoto C, Goto H, Nakase H, Tanaka S, Matsui T, Sugano K, Iida M: Prevalence of non-steroidal anti-inflammatory drug-induced enteropathy determined by double-balloon endoscopy: a Japanese multicenter study. Scand J Gastroenterol 2008;43:490-496. 